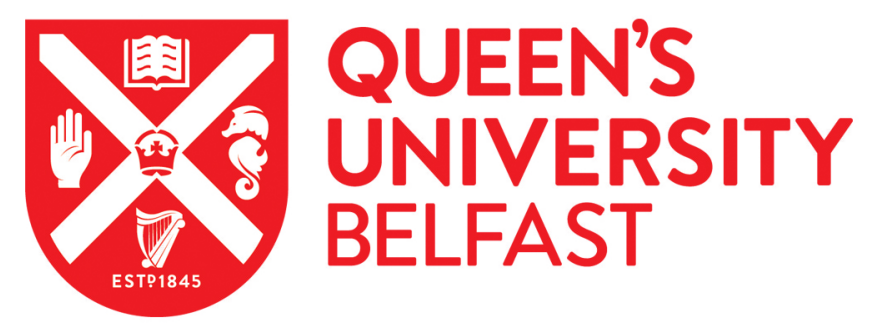

\title{
The influence of mobility on mental health status in young people: The role of area-level deprivation
}

Tseliou, F., Maguire, A., Donnelly, M., \& O'Reilly, D. (2016). The influence of mobility on mental health status in young people: The role of area-level deprivation. Health \& Place, 42, 96-103.

https://doi.org/10.1016/j.healthplace.2016.09.001

\section{Published in:}

Health \& Place

\section{Document Version:}

Peer reviewed version

Queen's University Belfast - Research Portal:

Link to publication record in Queen's University Belfast Research Portal

Publisher rights

( 2016 Elsevier Ltd This manuscript version is made available under the CC-BY-NC-ND 4.0 license http://creativecommons.org/licenses/by$\mathrm{nc}-\mathrm{nd} / 4.0 /$ which permits distribution and reproduction for non-commercial purposes, provided the author and source are cited

\section{General rights}

Copyright for the publications made accessible via the Queen's University Belfast Research Portal is retained by the author(s) and / or other copyright owners and it is a condition of accessing these publications that users recognise and abide by the legal requirements associated with these rights.

Take down policy

The Research Portal is Queen's institutional repository that provides access to Queen's research output. Every effort has been made to ensure that content in the Research Portal does not infringe any person's rights, or applicable UK laws. If you discover content in the Research Portal that you believe breaches copyright or violates any law, please contact openaccess@qub.ac.uk. 


\section{The influence of mobility on mental health status in young people: the role of area-level deprivation.}

\section{Introduction}

It has now been acknowledged that many of the antecedents to chronic poor mental health in adulthood arise during childhood and early adolescence (Kessler et al., 2005). One such factor that has been increasingly associated with poor mental health in early adulthood is childhood residential instability, though it is unclear which facets are causative (Ross et al., 2000; Leventhal and Brooks-Gunn, 2000; Aneshensel and Sucoff, 1996). Residential change in childhood can be the end product of a range of overlapping sociological factors and the associated psychological effects on the child can arise from both the processes that preceded or lead to the address change as well as from the effects of the address change itself.

Residential mobility hasn't only been linked to current household environment, but also to other circumstantial parameters such as the change in family structure due to divorce or childbirth, employment related reasons, change in tenure status and the quality of the neighbourhood (Rabe and Taylor, 2010). Some of these residential changes may also be associated with a positive change of circumstances, such as moving to a bigger and better house, or as a consequence of parental employment advancement, resulting in access to an improved physical environmental, including potentially better schools. In such cases, childhood residential mobility might act as a protective factor for later mental health, interacting with the individual's underlying personality traits (Oishi and Schimmack, 2010). However, in many circumstances the effects are not positive (Dewit, 1998). During the process of moving, children might become exposed to new neighbourhood and environments (Diez Roux, 2001). This change of both home and social environment is a stressful condition for the offspring of mobile families as they usually appear to be more susceptible to other detrimental effects, including poor school performance (Gasper et al., 2010) and decreased social capital (Gillespie, 2013), due to the disruption of social networks formation (Brown et al., 20102; Pettit, 2004; South and Haynie, 2004). Early life transitions may be indicative of a process of cumulative disadvantage where students who change residence and schools repeatedly, fail to adapt to new environments with skills shaped by their previous social context (Cotterell, 2007). Although, the way school and neighbourhood environments are structured, can differentiate the exposure of children to a range of stressors (Avison, 2010), mobile children face difficulties in establishing a sense of self due to a constantly changing environment (Wooster and Harris, 1972), thus being more likely to associate with peer groups that engage in delinquent behaviour (Eckert, 1989).

There are several aspects of residential change that contribute to the overall impact of moving on the individual, including the presence of social support from meaningful others (Hendershott, 1989). In the pursuit of understanding these parameters, several potential factors have been considered such as health status (Brown et al., 2012) and familial stability (Gilman et al., 2003), but relevant findings have been inconsistent. Marital dissolution due to divorce (or less frequently death of a parent) is a recognised confounding factor as it is a known source of poor mental health in children (Hayatbakhsh et al., 2013) and is often associated with a change of address (Gilman et al., 2003), though a recent study has demonstrated that frequent address change is still present in children living within stable family structures (Tseliou et al., 2015). These discrepancies can be attributed to the fact that adversity in early life may act through a series of inter-correlated life stressors cumulatively affecting mental health outcomes later in life (BoyntonJarrett et al., 2013). 
A number of previous studies have explored the role of migration and neighbourhood and area deprivation on mental health outcomes (Butler et al., 2012; Brown et al., 2012; Tunstall et al., 2012), but the main focus has been on the association with recent residential moves (Tunstall et al., 2014), instead of childhood mobility. There are further limitations due to methodological issues such as the use of parent-reported measures of deprivation, telephone-based survey procedures (Butler et al., 2012), self-reported measures of perceived environment (Aneshensel and Sucoff, 1996; Lenzi et al., 2012), attrition (Taylor et al., 2010), low response survey rates (Drukker et al., 2005), selection bias (Root and Humphrey, 2014) and the use cross-sectional study designs (Jelleyman and Spencer, 2008). These issues have led to uncertainty over the true effects of area deprivation on children's long-term mental health status, as it is yet unclear whether children who move, do so in similar areas and whether they maintain comparable trajectories in terms of socio-economic status with each residential move. The use of administrative data with full population cover would assist in an unbiased examination of the association of area deprivation and child mental health, by circumventing many of the issues related to selection and recall bias.

Thus, the association between childhood area mobility and later mental health problems needs to be further explored using representative samples of individuals to account for individual, family and household characteristics. Taking into account changing parental marital status as a measure of social support (Hendershott, 1989), as well as, both house value and tenure as a measure of different levels of mobility (Popham et al., 2015), could add to the current understanding on the ranging susceptibility of each individual's mental health status.

This study's aims were to determine: 1) if moving towards a less deprived area is associated with better mental health in adolescents and young adults, 2) if moving to a more deprived area is associated with a poor mental health status, 3) whether the observed association with mental health is moderated by the initial level of area deprivation (2001), the frequency of residential moves or other individual and household characteristics and 4) whether the association of interest is observed in both house renters and owners. 


\section{Methods}

This study implemented a record linkage using data extracted from the Northern Ireland Longitudinal Study (NILS). This is a representative sample of approximately $28 \%$ of the Northern Irish population based on a random selection of 104 dates of birth in the Health Card Registration Database (which ensures universal access to health care free at the point of delivery) linked to the 2001 \& 2011 Census returns for this study (see O'Reilly et al., 2012 for a more detailed description of the cohort and linkage methodology). The main aim of the current study was to create a cohort of individuals enumerated in both the 2001 and 2011 Censuses, measure the number of inter-censal address changes, determine whether they ended up on a more or less deprived area than in the beginning and then examine how these changes relate to self-assessed chronic poor mental health reported in the 2011 Census.

\subsection{Cohort characteristics}

Our cohort consisted of a representative sample of all non-institutionalised children in Northern Ireland, aged 0-8 years at the time of the 2001 Census who were also present and enumerated in the 2011 Census. Older individuals were excluded as there was a high probability that they would have moved out from their parental home ten years later, due to higher education or employment opportunities. Baseline individual characteristics were mainly determined according to the 2001 Census. This included the presence of a long-term illness limiting the person's daily activities (limiting long-term illness; LLTI) which was assessed through a yes/no response and was also included as an indicator of poor physical health (Cohen et al., 1995), as physical health has previously been linked to residential instability, in terms of healthcare needs of individuals with chronic conditions (Yantzi et al., 2001).

Parental marital status was considered as a potential confounding factor in our regression models, representing a measure of social support and a potential moderating factor (Hendershott, 1989). As we were interested in observing shifts in parental marital status between the two Census periods, we measured the number of parents at both time points and our variable was grouped to five categories: 2 parents at both time points; 2 parents going to 1 parent (where it was presumed that marital dissolution was the predominant attribute); 1 parent going to 2 parents; 1 parent at both time points; and other. The 'other' category included children who were supported by family members other than their parents. The total number of individuals in the household at 2001 was also included as a further measure of social support.

Socioeconomic status at baseline was assessed using household car availability (two or more; one only, no access) and a separate variable measuring both housing tenure and house value. House tenure-value included distinct categories for owners (grouped into six categories ranging from less than $£ 75 \mathrm{k}$ to over $£ 200 \mathrm{k}$ and accounting for owners with unvalued houses) and people who were renting (split to private and social renters). Data on house capital value were obtained as part of an exercise by central government in 2005 to determine the level of local tax payable by each household.

\subsection{Area deprivation}

Each of the jurisdictions within the UK has adopted a common methodology for identifying area disadvantage; in Northern Ireland this is called the Northern Ireland Multiple Deprivation Measure (NIMDM) (NISRA, 2010). This identifies seven separate domains of deprivation and an overall summary measure. We chose the income domain as the more apposite aspect of deprivation for this study. This measure is based on the proportion of people experiencing income deprivation at the small area level through the use of a non-overlapping count of individuals living in households receiving means-tested social security benefits. The deprivation measure was calculated at the level of Census super-output area (SOA), a standard governmental administrative geographical unit comprising on average 1800 individuals in 2001 (NISRA, 2010) that is generated to be similar in population size unlike electoral ward boundaries. The measure, grouped into quintiles of the population, was utilised to ensure that there will be no 
disclosure risks. As this measure has been updated in 2005 and 2010, we used the recommended measure of assessment (NISRA, 2010) to avoid conflating the effects of residential movement and reclassification of areas.

The geography of 6 SOAs were slightly modified between 2001 and 2011 which would have led to some individuals appearing as either having moved across quintiles $(\mathrm{N}=446)$ or having no information of area of residence in 2011 $(\mathrm{N}=428)$. These 874 individuals were further investigated in terms of socio-demographic characteristics, and as they were not different from the rest of population, they were excluded from the analysis under the assumption that they were missing at random, with the final cohort changing from 49762 to 48888 individuals (see Tseliou et al., 2015 for the initial cohort).

\subsection{Area mobility}

This study recognises two types of internal migration; the first being a simple count of the number of address changes experienced by the child; the second identified whether over the ten years of the study the child was living in a more or less deprived area, i.e. only movements between and within categories were assessed. These two types of mobility were assessed by using two different sources of data, GP records (for residential change) and Census returns (for area change). Residential mobility during the ten years of follow up was based on updates received by the Health Card Registration Database. When a patient informs their General Practitioner (GP) of an address change the information on the new address is automatically added to the central Registration database. NILS receives updates biannually from the Registration database, so this study could have recorded up to twenty address changes for each cohort member during the ten years follow up period.

Area mobility was calculated by comparing the level of area deprivation in both 2001 and 2011. The variable was measured in quintiles ranging from 1 (least deprived) to 5 (most deprived). For our study, we merged these into three categories by combining the areas falling within the more deprived quintiles ( 4 and 5 ) to account for the most deprived category, the areas falling within the less deprived quintiles ( 1 and 2 ) to account for the least deprived category and the areas in the middle quintile (3) as the intermediate category, in order to avoid a breach of confidentiality due to small numbers observed in the extreme groups (1=least deprived and 5=most deprived) both at the 2001 and 2011 Censuses. This allowed us to perform further analysis on area mobility and accurately control for the level of area of deprivation in 2001. Thus, using these groups from both 2001 and 2011 Census returns, three categories were created in order to account for: no change, improvement (change by at least one category towards less deprived areas) and downgrade (change by at least one category towards more deprived areas) between the two Censuses.

\subsection{Main outcome}

The main outcome of our analysis was the likelihood of reporting a chronic mental health condition. This was determined using a Northern Ireland question in the 2011 Census, which asked about the presence of a range of chronic morbidity ("Do you have any of the following conditions which have lasted, or are expected to last, at least 12 months?"). There was a list of twelve conditions that were available to individuals. For this study, the focus was placed on the category "an emotional, psychological or mental health condition (such as depression or schizophrenia)", which was used as a binary variable. It has been previously suggested that self-reported health 'clearly measure(s) something more-and something less-than objective medical ratings' (Maddox and Douglass, 1973). This measure has demonstrated a high degree of correlational and predictive validity (in separate, yet unpublished analysis) providing similar estimations with the General Health Questionnaire (GHQ).

A proportion of individuals with "a learning difficulty, an intellectual difficulty, or a social or behavioural difficulty" $(n=2,096)$ were excluded from the main analysis, as it was expected that a higher prevalence of poor mental health status would be related to the underlying condition rather than any effect arising from area mobility, thus producing a spurious association for between area change and poor mental health. 
For the purpose of assessing mobility across deprivation categories, we created a variable by using data on the number of residential moves and the area level of deprivation. This variable consisted of three categories: downgrade including individuals moving towards a more deprived area; improvement including those who moved towards a less deprived area; and no change including those who did not experience a change in terms of area level of deprivation. Descriptive statistics were used to outline the cohort characteristics and the association between socio-demographic characteristics of each cohort member, their household conditions and residential mobility across different areas. Logistic regression models were utilised to explore the association between area level change of address and poor mental health, with area mobility tested as a categorical variable (no change, downgrade and improvement). Models were adjusted for additional differences in terms of individual characteristics, family composition and socioeconomic status. Tests for interaction were used to determine if the association of interest varied according to these characteristics.

A number of sensitivity analyses were undertaken. The first restricted the cohort by excluding individuals aged over 16 years at the time of the 2011 Census in order to further control for people leaving home for job or education opportunities. The second excluded people who were renting their property to explore whether the association of interest is observed in both house owners and renters, as the latter group is expected to be more mobile than the former. Finally, a third sensitivity analysis was undertaken, with the cohort members grouped as residing in least deprived (1), intermediate $(2+3+4)$ and most deprived (5) quintiles.

The linked data were anonymised, held in a secure environment by the Northern Ireland Statistics and Research Agency (NISRA) and made available to the research team for the purpose of this study. The use of the NILS for research was approved by the Office for Research Ethics Committees Northern Ireland (ORECNI). 


\section{Results}

The cohort consisted of 48,888 individuals aged between 0 and 8 years at the 2001 Census, with a mean age of 4.4 years (sd. 3.2) and almost equal numbers of males and females (50.1\% and $49.9 \%$ respectively). Table 1 presents a detailed description of their characteristics; Table 2 further explores the link between residential moves and area deprivation; and Tables 3 and 4 address the main aims of the study by focusing on mental health status. A small proportion (4.3\%) reported a limiting long-term illness at the 2001 Census. In terms of family status, the majority of children $(n=30,827)$ were living in two-parent families at both time points while approximately $15 \%$ were living in one parent families and 3\% with other family members instead of the parents. A small proportion of the cohort was residing in households characterised by a low socio-economic status such as house value under $€ 75 k(n=2,663)$, social renting $(n=8,890)$ and no car ownership $(n=7,904)$.

\section{Insert table 1 here}

During the ten-year follow-up period, 26,504 (54.2\%) individuals have experienced at least one residential change. More specifically, 3,174 members of the cohort experienced a residential move that resulted in moving towards a more deprived area. The individual's gender and physical health at 2001 was not associated with area change. Area mobility towards more deprived areas was more frequently observed (21.2\%) among families with marital dissolution ( 2 parents at baseline, 1 parent at the 2011 Census). Two parent families presented a higher proportion of no area change (65.5\%) and a higher proportion of families that changed from one parent to two parents at follow-up moved towards a less deprived area (12.2\%) along with single parent families (17.3\%). Reduced mobility across areas was related to big household size ( 5 or more residents), occupation of more affluent houses (150k or more). On the contrary, area mobility towards more deprived areas was linked to socio-economic status and individuals in social rented accommodation or in households without access to cars. Finally, it can be noted that a higher proportion of individuals, who moved four or more times, experienced a downgrade in area deprivation when compared to those who moved less frequently.

Table 2 illustrates the movement of cohort members across areas that are characterised by different levels of deprivation. It appears that the majority of the population remains in socio-economically similar areas when comparing the time points of the two Censuses (2001\&2011). Those who moved into more deprived areas from less deprived areas seemed more likely to have experienced a higher number of residential moves when compared with individuals that either moved up socially or experienced no such change. Furthermore, elevated rates of poor mental health were observed in those who moved in deprived areas. However, this finding cannot be presented here due to low numbers potentially breaching confidentiality.

\section{Insert table 2 here}

Table 3 shows the logistic regression models that were built to further explore the association between area mobility and poor mental health as well as the moderating role of individual, household and socio-economic factors. The models used confirm the association between mental health status, area deprivation and residential mobility. Moving from a less to a more deprived area was associated with an increased likelihood of reporting poor mental health status in 2011 (OR 2.11; 95\%Cls 1.45-3.07), when compared to moving from a more to a less deprived area. This association remained significant even after adjusting for individual and household variables at baseline, but was greatly attenuated and did not reach statistical significance when the number of residential moves was accounted for (OR 1.54; $95 \% \mathrm{Cls}$ 0.99-2.41). 
The likelihood of reporting poor mental health was over twice as likely among offspring of single parent families (OR 2.15; 95\% Cis 1.45-3.18), an effect that was initially observed for families experiencing marital dissolution but was slightly ameliorated after adjusting for the total number of residential moves. The effect of socio-economic status was also evident as individuals in low value properties were approximately three times more likely to report poor mental health when compared to owners of affluent households. The increased risk was also evident among residents of both private and social renting accommodation who were twice as likely to have poor mental health (ORs 2.30; $95 \%$ Cis 1.09-4.84 and 2.59; 95\% Cis 1.26-5.31 respectively).

\section{Insert table 3 here}

There was a gradient effect of residential change on the relationship between area mobility and poor mental health status, with individuals experiencing three or more residential moves during the inter-censal period being twice as likely to report a mental health condition (ORs 1.87; 95\% Cis 1.19-2.93 and 2.21; 95\% Cis 1.30-3.76) than non-movers. This effect was stronger in those who have experienced more than five residential moves (OR 2.89; 95\% Cls 1.78-4.69), suggesting that the role of change of address is important when exploring the association between area change and mental health status.

A series of sensitivity analyses were carried out (models available upon request). The first analysis showed that the association between area mobility and mental health status yielded similar results, even when including only those aged 16 years and under in 2011. The second analysis explored the exclusion of those who, at the time of the 2001 Census, were either in private or social renting accommodation and demonstrated a similar effect of area mobility. However, unlike the main analysis, when controlling for the number of residential moves for renters, an increased number of residential moves did not have an effect on the association between area mobility and mental health status (OR 1.53; 95\% Cls $0.53-4.48$ for those who experienced five or more residential moves). This could be due to the fact that renters are a more mobile group than property owners and removing them resulted in the attenuation of the gradient effect of moves. The third sensitivity analysis, utilising different area deprivation categories, retained a similar level of association between the variables of interest with main analysis (full model of this analysis are available in the appendix).

Moving towards a more deprived area was associated with the individual's mental health but there is still a need to look in more detail to the effect of moving across areas with different levels of deprivation. In particular, further analysis is required to clarify whether moving from less to more deprived areas only or any change of socio-economic status can be linked to poorer mental health status.

Table 4 shows the association between moving to or out of a more deprived area for each category of deprivation and the likelihood of reporting poor mental health with the stable population acting as the reference group. For those individuals resident in a least deprived area in 2001, moving to an intermediate or most deprived area is linked to poor mental health. Moving from most to least deprived areas is suggestive of having a positive association with mental health. However, results do not appear to be statistically significant.

\section{Insert table 4 here}

Evidence of the effect of area mobility could also be noted even in the model adjusting for the total number of residential moves. Adding to the link between moving from a least deprived or intermediate area towards a most deprived area and poor mental health (ORs 1.64; 95\% Cls 0.7-3.52 and 1.56; 95\% Cls 0.67-3.59 respectively), a trend can also be observed, suggesting that individuals moving from a most deprived area towards an intermediate or least 
deprived area may act as a protective factor for reporting poor mental health (ORs 0.87; 95\% Cls 0.43-1.75 and 0.87; $95 \%$ Cls 0.43-1.75 respectively).

The amelioration of the effect of area mobility in the final model could suggest that individuals who ended up in a more deprived area might have experienced more residential moves, gradually moving down the social gradient, moderating the overall impact on the individual. 


\section{Discussion}

\subsection{Main findings}

This study shows that moving from a less to a more deprived area in childhood may be associated with poor mental health, independent of a number of individual and household variables. This relationship is not wholly an outcome of the area per se but rather the total number of residential moves experienced by the individual between the two Censuses plays a major moderating role in the association. Household socio-economic status of the individual, including household tenure, should also be considered in the interpretation of the overall effect of mobility on the offspring. No significant association with mental health status was noted for those moving towards a more deprived area.

\subsection{Interpretation of the results}

This study adds to the existing literature linking mobility, area deprivation and the presence of mental health and emotional conditions. In particular, it was hypothesised that the higher rates of poor mental health could be associated to a range of mediators, such as the increased number of residential moves, experienced by cohort members that moved towards deprived areas. This is confirmed by the fact that adjusting for number of residential moves had a considerable effect on the overall impact of area change. The impact of housing tenure, which has been strongly associated with health, is linked to housing quality, neighbourhood conditions and other socioeconomic factors that vary among people with different tenure status (Ellaway et al., 2004). As changes in tenure usually require housing moves, which may be stressful and linked to major life events, it is of interest to explore whether the impact of tenure status per se is an important risk factor for health, independent of residential mobility. Moving house can be associated with temporary pre-move rises in distress, deriving from the changes due to the forthcoming move (Nowok et al., 2013). Thus, although moving down the social stratum is linked to poor mental health, the role of residential change needs to be taken into consideration.

However, when considering potential moderators, initial area of residence should also be taken into account and it is important to note that those residing in deprived areas at the time of the 2001 Census were more likely to report a mental health condition. Evidence for such an association between neighbourhood deprivation and measures of child well-being has been previously shown to occur through a variety of pathways (Kohen et al., 2008; Mair et al., 2008; Odgers et al., 2009). A number of measures of area-level deprivation have been previously described, focusing on different aspects of the environment such as socio-economic conditions as well as health-related dimensions of physical environment (Richardson et al., 2010). In our study, we utilised a measure of income deprivation on an area level, in order to better account for monetary poverty and its association with individual and household level variables, an aspect that could not be assessed by the remaining domains of deprivation. Differences in ill-health outcomes could be attributed to the relative deprivation of the area of residence even after considering individual characteristics of the population residing in those particular areas (Boyle et al., 2004).

Familial factors may also be contributing, the effect of area mobility on mental health tended to vary and was attenuated when controlling for parental change between the 2001 and 2011 Census. According to the ecological systems theory, the characteristics of the multiple socio-environmental domains in which a child functions contribute to health and developmental well-being (Bronfenbrenner, 1974). Therefore, the examination of individual characteristics in isolation from the contexts within which children live is an insufficient measure, as children exist simultaneously in multiple contexts and each of these may determine well-being throughout childhood. For this reason, mental health can only be understood within the context of a complex environment (Diez Roux and Mair, 2010), where development occurs.

Furthermore, the association between area deprivation and mental health was maintained for both renters and property owners and was thus, not mediated by tenancy status as the observed effect did not vary substantially when the analysis was performed using the individuals that were identified as property owners. Previous studies have indicated that actual or perceived status, such as house tenure, can have an impact on health through stress-inducing 
conditions (Wilkinson and Pickett, 2010), while house ownership can be beneficial in terms of health (Shaw, 2004) and future academic achievement (Chen, 2013). Nevertheless, the impact of area change manifested as a gradient effect dependent on the property value and whether the residents were in private or social renting.

In terms of mobility patterns, the number of individuals moving from the most towards the least deprived areas appeared to be greater than was observed moving in the opposite direction or remaining within areas with a similar level of deprivation. Collectively this would suggest a net population movement out of the more deprived areas between the two Censuses, a finding consistent with previous research (Connolly et al., 2011). Pettit and McLanahan (2003) have shown that families who moved to better neighbourhoods were more likely to have economic and social resources. However, the stability of neighbourhoods is also a potential contributing factor on the effect that deprivation can have on psychological distress (Ross et al., 2000). According to the social isolation perspective, deprivation in poor stable neighbourhoods may be more distressing, as stability resembles feelings of being trapped and powerless in a dangerous and frightening place, an effect that is not observed in residentially unstable neighbourhoods. Neighbourhoods with low residential turnover are also reported to have higher levels of social cohesion (social capital) (Aneshensel and Sucoff, 1996), which has been reported to be associated with better mental health.

Through further exploration of these patterns, a category shift was implied as people tended to move from least to most deprived areas as well as from most to least deprived in large numbers, when compared to those that simply moved by one category. This was an unusual finding as individuals are usually expected to move to more similar areas (for example from a least deprived to an intermediate area), but could be attributed to the fact that the area of residence was assessed only in 2001 and in 2011 or our decision to combine the two most deprived quintiles and the two least deprived quintiles using the middle category as the intermediate.

\subsection{Strengths and limitations}

For the purpose of our study, a large representative sample of individuals and households in Northern Ireland was utilised. The longitudinal aspect of the data allowed for the exploration of the impact of area changes in relation to related changes in address and mental health. By using information on the NIMDM dimensions to create a variable assessing the level of area deprivation, we captured an adequate representation of area context to which the individual might be exposed. The study's record-linkage methodology also adds to its strength through the combination of Census data describing the socio-spatial characteristics of moves with information on the frequency of residential moves from the administrative sources.

However, this study has several methodological limitations deriving from the nature of the data. In more detail, the use of secondary data leads to limitations as the analysis was implemented only on sample characteristics that have been previously collected. We adjusted for a range of potential confounding factors but individuals moving into deprived or not moving out of deprived areas may differ from their peers, in terms of factors that were not assessed in this study. Another major limitation is the fact that poor mental health was assessed through the use of a selfreported question, thus leading to a potential underestimation of the true effect of area mobility on the offspring and the true prevalence rates of mental health conditions in this age group. Low rates of mental ill-health could stem from the fact that the Census question enquires about the presence of a chronic mental health condition, not taking into account acute or recent events. Although the measure was not included in the 2001 Census, the possibility of reverse association is very unlikely as this cohort would be aged less than 8 years at the 2001 Census, with the likelihood of a chronic emotional/ psychological condition being extremely low at that age. It is also possible that the development of mental health problems during the inter-censal period could be linked to increased mobility between 2001 and 2011, though the effect of physical ill-health in the association of interest should also be taken into consideration. 
It should also be noted that measures of socio-economic status and residential instability can only be used as proxy measures for the underlying social processes, which affect child and adolescent mental health in maladaptive environments. Furthermore, the effect of school moves was not accounted for, although, residential mobility is often accompanied by a change of school. Relevant research has proposed that the association between residential mobility and behaviour problems is driven by school mobility rather than residential change itself (Gasper et al., 2010). Finally, although, the association between area mobility, change of address and poor mental health was evident, a causal relationship cannot be proven due to the observational design of this study.

\subsection{Implications}

This study hints at the importance of childhood area mobility on mental health status in adolescence and early adulthood. It could be suggested that this effect on mental health needs to be further highlighted especially for populations residing in more deprived areas.

There are multiple reasons for families to change residence which may directly relate to the type of the environment they move into and out of (Root, 2012). Future research should further explore residential mobility focusing on the determinants of residential mobility, the disruption caused by moving, as well as the results of mobility in order to understand the relative effect of each factor on mental health. Individuals experiencing frequent residential moves might reside in unstable households with poor mental health being related to this lack of stability. These questions are of substantial importance in terms of policy making by directing the focus on supporting family stability within changing neighbourhood structures.

\subsection{Conclusion}

The impact of childhood area mobility on mental health status during adolescence and early adulthood was investigated in this study. We suggest that residential mobility over a 10-year time period may have a mediating effect on the relationship between area level of deprivation and poor mental health among young adults.

\section{Acknowledgements}

The help provided by the staff of the Northern Ireland Longitudinal Study (NILS) and the NILS Research Support Unit is acknowledged. The NILS is funded by the Health and Social Care Research and Development Division of the Public Health Agency (HSC R\&D Division) and NISRA. The NILS-RSU is funded by the ESRC and the Northern Ireland Government. The authors alone are responsible for the interpretation of the data and any views or opinions presented are solely those of the author and do not necessarily represent those of NISRA/NILS.

\section{Competing interests: None.}




\section{References}

Aneshensel, C.S., Sucoff, C.A., 1996. The neighborhood context of adolescent mental health. J. Health. Soc. Behav. 37, 293-310.

Avison, W.R., 2010. Incorporating children's lives into a life course perspective on stress and mental health. J. Health. Soc. Behav. 51(4), 361-75.

Boyle, P., Norman, P., Rees, P., 2004. Changing places. Do changes in the relative deprivation of areas influence limiting long-term illness and mortality among non-migrant people living in non-deprived households? Soc. Sci. Med. 58, 24592471.

Boynton-Jarrett, R., Hair, E., Zuckerman, B., 2013. Turbulent times: effects of turbulence and violence exposure in adolescence on high school completion, health risk behavior, and mental health in young adulthood. Soc. Sci. Med. $95,77-86$.

Bronfenbrenner, U., 1974. Developmental research, public policy, and ecology of childhood. Child. Dev. 45, 1-5.

Brown, D., Benzeval, M., Gayle, V., Macintyre, S., O’Reilly, D., Leyland, A.H., 2012. Childhood residential mobility and health in late adolescence and adulthood: findings from the West of Scotland Twenty-07 Study. J. Epidemiol. Community. Health. 66(10), 942-950.

Butler, A.M., Kowalkowski, M., Jones, H.A., Raphael, J.L., 2012. The Relationship of Reported Neighborhood Conditions with Child Mental Health. Acad. Pediatr. 12(6), 523-531.

Chen, J., 2013. Housing tenure, residential mobility and adolescents' education achievement: evidence from Sweden. Ann Reg Sci. 50(1); 275-294.

Cohen, G., Forbes, J., Garraway, M., 1995. Interpreting self reported limiting long term illness. B.M.J. 311, 722-4.

Connolly, S., Rosato, M., O'Reilly, D., 2011. The effect of population movement on the spatial distribution of socioeconomic and health status: analysis using the Northern Ireland mortality study. Health Place. 17(4), 1007-10.

Cotterell, J., 2007. Social Networks in Youth and Adolescence (2nd ed.). London: Routledge.

Dewit, D.J., 1998. Frequent childhood geographic relocation: its impact on drug use initiation and other drug-related problems among adolescents and young adults. Addict. Behav. 23(5), 623-34.

Diez Roux, A.V., Mair, C., 2010. Neighborhoods and health. Ann. N. Y. Acad. Sci. 1186, 125-45.

Diez Roux, A.V., 2001. Investigating neighborhood and area effects on health. Am. J. Public Health. 91(11), 1783-1789.

Drukker, M., Kaplan, C., van Os, J., 2005. Residential instability in socioeconomically deprived neighbourhoods, good or bad? Health Place. 11(2), 121-9.

Eckert, P., 1989. Jocks and burnouts: Social categories and identity in the high school. New York: Teachers College Press.

Ellaway, A., McKay, L., Macintyre, S., et al., 2004. Are social comparisons of homes and cars related to psychosocial health? Int. J. Epidemiol. 33, 1065-71. 
Gasper, J., DeLuca, S., Estacion, A., 2010. Coming and going: explaining the effects of residential and school mobility on adolescent delinquency. Social Science Research. 39, 459-476.

Gillespie, B.J., 2013. Adolescent behavior and achievement, social capital, and the timing of geographic mobility. Adv. Life. Course. Res. 18(3), 223-33.

Gilman, S.E., Kawachi, I., Fitzmaurice, G.M., Buka, L., 2003. Socioeconomic status, family disruption and residential stability in childhood: relation to onset, recurrence and remission of major depression. Psychol. Med. 33(8), 13411355.

Hayatbakhsh, R., Clavarino, A.M., Williams, G.M., et al., 2013. Family structure, marital discord and offspring's psychopathology in early adulthood: a prospective study. Eur. Child. Adolesc. Psychiatry. 22(11), 693-700.

Hendershott A.B., 1989. Residential mobility, social support and adolescent self-concept. Adolescence. 24(93), 21732.

Jelleyman T, Spencer N. Residential mobility in childhood and health outcomes: a systematic review. J. Epidemiol. Community Health 2008;62(7): 584-592.

Kessler, R.C., Berglund, P., Demler, O., Jin, R., Merikangas, K.R., Walters, E.E., 2005. Lifetime prevalence and age-ofonset distributions of DSM-IV disorders in the National Comorbidity Survey Replication. Arch. Gen. Psychiatry. 62(6), 593-602.

Kohen, D.E., Leventhal, T., Dahinten, V.S., McIntosh, C.N., 2008. Neighborhood disadvantage: pathways of effects for young children. Child Development. 79, 156-169.

Lenzi, M., Vieno, A., Perkins, D.D., Pastore, M., Santinello, M., 2012. Perceived neighborhood social resources ad determinants of prosocial behavior in early adolescence. Am. J. Community Psychol. 50(1-2), 37-49.

Leventhal, T., Brooks-Gunn, J., 2000. The neighborhoods they live in: the effects of neighborhood residence on child and adolescent outcomes. Psychol. Bull. 126(2), 309-37.

Maddox, G.L., Douglass, E.B., 1973. Self-assessment of health: a longitudinal of elderly subjects. J. Health Soc. Behav. 14(1), 87-93.

Mair, C., Diez Roux, A.V., Galea, S., 2008. Are neighbourhood characteristics associated with depressive symptoms? a review of evidence. J. Epidemiol. Community Health. 62, 940-946.

NISRA, 2010. Northern Ireland Statistics and Research Agency: Northern Ireland Multiple Deprivation Measure.

Nowok, B., van Ham, M., Findlay, A.M., et al., 2013. Does migration make you happy? A longitudinal study of internal migration and subjective well-being. Environ. Plann. A. 45, 986-1002.

O’Reilly, D., Rosato, M., Catney, G., Johnston, F., Brolly, M., 2012. Cohort description: the Northern Ireland Longitudinal Study (NILS). Int. J. Epidemiol. 41(3), 634-41.

Odgers, C.L., Moffitt, T.E., Tach, L.M., Sampson, R.J., Taylor, A., Matthews, C.L., Caspi, A., 2009. The protective effects of neighborhood collective efficacy on British children growing up in deprivation: a developmental analysis. Developmental Psychology. 45, 942-957.

Oishi, S., Schimmack, U., 2010. Residential mobility, well-being, and mortality. J. Pers. Soc. Psychol. 98(6), 980-94. 
Pettit, B., McLanahan, S., 2003. Residential mobility and children's social capital: evidence from an experiment. Social Science Quarterly. 84, 632-649.

Pettit, B., 2004. Moving and children's social connections. Sociol. Forum. 19, 285-311.

Popham, F., Williamson, L., Whitley, E., 2015. Is changing status through housing tenure associated with changes in mental health? Results from the British Household Panel Survey. J. Epidemiol. Community Health. 69, 6-11.

Rabe, B., Taylor, M., 2010. Residential mobility, quality of neighbourhood and life course events. J R Stat Soc Ser A Stat Soc. 173(3), 531-555.

Richardson, E.A., Mitchell, R., Shortt, N.K., et al., 2010. Developing summary measures of health-related multiple physical environmental deprivation for epidemiological research. Environ. Plann. A. 42(7), 1650-68.

Root, E.D., Humphrey, J.L., 2014. The impact of childhood mobility on exposure to neighborhood socioeconomic context over time. Am. J. Public Health. 104, 80-82.

Root, E.D., 2012. Moving neighborhoods and health research forward: using geographic methods to examine the role of spatial scale in neighborhood effects on health. Ann. Assoc. Am. Geogr. 102, 986-995.

Ross, C.E., Reynolds, J.R., Geis, K.J., 2000. The contingent meaning of neighborhood stability for residents' psychological well-being. American Sociological Review. 65, 581-597.

Shaw, M., 2004. Housing and public health. Annu. Rev. Public Health. 25, 397-418.

South, S.J., Haynie, D.L., 2004. Friendship networks of mobile adolescents. Soc. Forces. 83, 315-350.

Taylor, M.F., Brice, J., Buck, N., et al., 2010. British household panel survey user manual volume a: introduction, technical report and appendices. Colchester: University of Essex.

Tseliou, F., Maguire, A., Donnelly, M., O'Reilly, D., 2015. The impact of childhood residential mobility on mental health outcomes in adolescence and early adulthood: a record linkage study. J. Epidemiol. Community Health. pii: jech-2015206123.

Tunstall, H., Cabieses, B., Shaw, R., 2012. The characteristics of mobile families with young children in England and the impact of their moves on neighbourhood inequalities in maternal and child health. Health Place. 18(3), 657-670.

Tunstall, H., Pearce, J.R., Shortt, N.K., Mitchell, R.J., 2014. Residential mobility and the association between physical environment disadvantage and general and mental health. Journal of Public Health. pp. 1-10.

Wilkinson, R., Pickett, K., 2010. The spirit level: why equality is better for everyone. London: Penguin.

Wooster, A.D., Harris, G., 1972. Concepts of self and other in highly mobile service boys. Educational Research. 14(3), 195-199.

Yantzi, N., Rosenberg, M.W., Burke, S.O., Harrison, M.B., 2001. The impacts of distance to hospital on families with a child with a chronic condition. Soc. Sci. Med. 52(12), 1777-91. 
Table 1

Characteristics of the cohort at the time of the 2001 Census and the characteristics of those who have moved within and across different levels of area deprivation between 2001 and 2011. Data represent: $N$ (\%). N=48,888

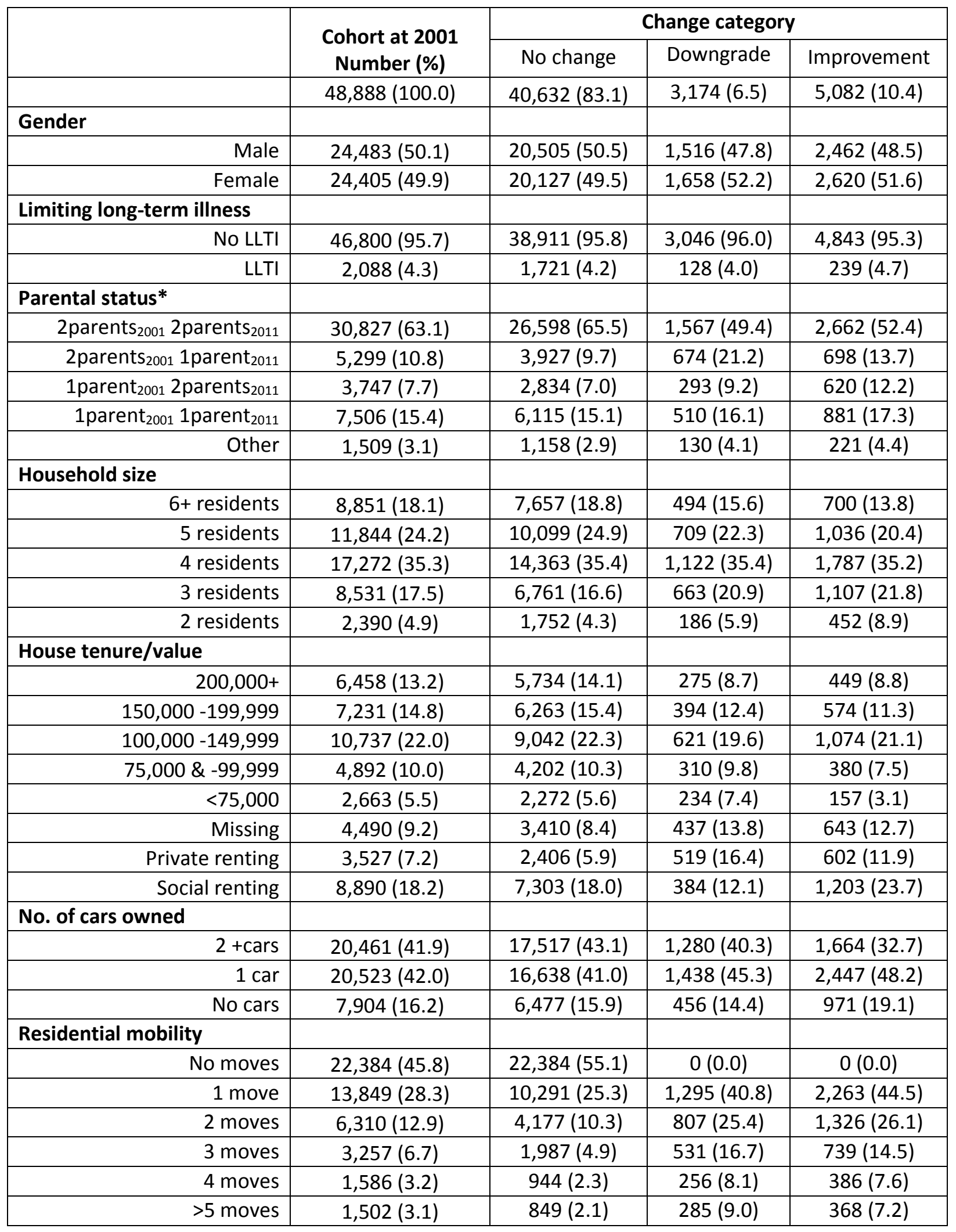

*Parental status: This represents number of parents present at 2001 and at 2011 


\section{Table 2}

Data represent number of people who have experienced at least one change of address (by 2011) by level of area deprivation in both 2001 and 2011 Censuses, percentages of individuals in each category and mean of number of residential moves. $\mathrm{N}=48,888$

\begin{tabular}{|c|c|c|c|}
\hline & Least deprived2011 & Intermediate 2011 & Most deprived 2011 \\
\hline Least deprived 2001 & $16,800(34.4)$ & $1,073(2.2)$ & $1,126(2.3)$ \\
Number (\%) & 0.70 & 2.04 & 2.28 \\
Mean of residential moves & $1,499(3.1)$ & $7,511(15.4)$ & $975(2.0)$ \\
\hline Intermediate 2001 & 1.96 & 0.64 & 2.24 \\
Number (\%) & $2,186(4.5)$ & $1,397(2.9)$ & $16,321(33.4)$ \\
Mean of residential moves & 2.09 & 2.15 & 0.99 \\
\hline Most deprived 2001 & & & \\
Number (\%) & &
\end{tabular}


Table 3

The proportion and likelihood of cohort members reporting poor mental health at the 2011 Census and the relationship to area mobility; data represent numbers (\%), and odds ratios $(95 \% \mathrm{Cls})$ from logistic regression models. $\mathrm{N}=48,888$ with $259(0.5 \%)$ cohort members reporting poor mental health

\begin{tabular}{|c|c|c|c|c|c|c|c|c|}
\hline & & $\begin{array}{l}\text { Poor mental } \\
\text { health } \mathrm{N}(\%)\end{array}$ & Model 1 & Model 2 & Model 3 & Model 4 & Model 5 & Model 6 \\
\hline Area change & $\begin{array}{l}\text { No change } \\
\text { Least to most deprived } \\
\text { Most to least deprived }\end{array}$ & $\begin{array}{l}195(0.5) \\
32(1.0) \\
32(0.6)\end{array}$ & $\begin{array}{c}1.00 \\
2.11(1.45-3.07) \\
1.31(0.90-1.91)\end{array}$ & $\begin{array}{c}1.00 \\
2.16(1.48-3.15) \\
1.36(0.93-1.98)\end{array}$ & $\begin{array}{c}1.00 \\
1.86(1.27-2.72) \\
1.20(0.82-1.75)\end{array}$ & $\begin{array}{c}1.00 \\
1.87(1.27-2.76) \\
1.19(0.81-1.74)\end{array}$ & $\begin{array}{c}1.00 \\
1.95(1.28-2.99) \\
1.19(0.80-1.75)\end{array}$ & $\begin{array}{c}1.00 \\
1.54(0.99-2.41) \\
0.96(0.64-1.45)\end{array}$ \\
\hline Age & Per year & $\mathrm{N} / \mathrm{A}$ & & 1.07 (1.05-1.09) & $1.05(1.03-1.07)$ & 1.05 (1.04-1.07) & 1.05 (1.04-1.07) & $1.06(1.04-1.08)$ \\
\hline Sex & $\begin{array}{r}\text { Male } \\
\text { Female }\end{array}$ & $\begin{array}{c}96(0.4) \\
163(0.7) \\
\end{array}$ & & $\begin{array}{c}1.00 \\
1.72(1.33-2.22) \\
\end{array}$ & $\begin{array}{c}1.00 \\
1.67(1.30-2.16) \\
\end{array}$ & $\begin{array}{c}1.00 \\
1.65(1.28-2.13) \\
\end{array}$ & $\begin{array}{c}1.00 \\
1.65(1.28-2.13) \\
\end{array}$ & $\begin{array}{c}1.00 \\
1.61(1.25-2.08) \\
\end{array}$ \\
\hline LLTI & $\begin{array}{r}\text { No LLTI } \\
\text { LLTI }\end{array}$ & $\begin{array}{l}235(0.5) \\
24(1.2) \\
\end{array}$ & & $\begin{array}{c}1.00 \\
2.14(1.39-3.29) \\
\end{array}$ & $\begin{array}{c}1.00 \\
1.80(1.17-2.78) \\
\end{array}$ & $\begin{array}{c}1.00 \\
1.67(1.08-2.57) \\
\end{array}$ & $\begin{array}{c}1.00 \\
1.66(1.08-2.57) \\
\end{array}$ & $\begin{array}{c}1.00 \\
1.65(1.07-2.54) \\
\end{array}$ \\
\hline Parental Status & $\begin{array}{r}2 \text { parents at both } \\
2 \text { to } 1 \text { parent } \\
1 \text { to } 2 \text { parents } \\
1 \text { parent at both } \\
\text { Other }\end{array}$ & $\begin{array}{l}89(0.3) \\
40(0.8) \\
20(0.5) \\
77(1.0) \\
33(2.2)\end{array}$ & & & $\begin{array}{c}1.00 \\
2.42(1.66-3.53) \\
1.73(1.06-2.81) \\
3.37(2.47-4.58) \\
5.38(3.45-8.37)\end{array}$ & $\begin{array}{c}1.00 \\
2.02(1.37-2.98) \\
1.34(0.79-2.27) \\
2.36(1.60-3.48) \\
3.96(2.46-6.38)\end{array}$ & $\begin{array}{c}1.00 \\
2.01(1.37-2.96) \\
1.34(0.79-2.27) \\
2.35(1.59-3.46) \\
3.94(2.44-6.35)\end{array}$ & $\begin{array}{c}1.00 \\
1.76(1.18-2.60) \\
1.26(0.74-2.14) \\
2.15(1.45-3.18) \\
3.30(2.02-5.37)\end{array}$ \\
\hline Household size & $\begin{array}{r}\text { >=6 residents } \\
5 \text { residents } \\
4 \text { residents } \\
3 \text { residents } \\
1-2 \text { residents }\end{array}$ & $\begin{array}{l}46(0.5) \\
56(0.5) \\
86(0.5) \\
55(0.6) \\
16(0.7)\end{array}$ & & & & $\begin{array}{c}1.00 \\
1.12(0.76-1.68) \\
1.17(0.81-1.68) \\
1.10(0.74-1.65) \\
0.75(0.41-1.37)\end{array}$ & $\begin{array}{c}1.00 \\
1.13(0.76-1.68) \\
1.17(0.81-1.68) \\
1.10(0.74-1.66) \\
0.75(0.41-1.37)\end{array}$ & $\begin{array}{c}1.00 \\
1.11(0.75-1.65) \\
1.15(0.80-1.66) \\
1.09(0.72-1.63) \\
0.74(0.40-1.34)\end{array}$ \\
\hline $\begin{array}{r}\text { House Tenure/ } \\
\text { Value }\end{array}$ & $\begin{array}{r}>200.000 \\
>150-<199,999 \\
>100-149,999 \\
>75-<99,999 \\
<75.000 \\
\text { Missing } \\
\text { Private renting } \\
\text { Social renting }\end{array}$ & $\begin{array}{l}12(0.2) \\
25(0.4) \\
40(0.4) \\
25(0.5) \\
23(0.9) \\
13(0.3) \\
31(0.9) \\
90(1.0)\end{array}$ & & & & $\begin{array}{c}1.00 \\
1.78(0.89-3.58) \\
1.66(0.85-3.23) \\
1.87(0.91-3.84) \\
3.04(1.45-6.36) \\
1.36(0.61-3.01) \\
2.76(1.33-5.72) \\
2.85(1.43-5.70)\end{array}$ & $\begin{array}{c}1.00 \\
1.78(0.89-3.58) \\
1.66(0.85-3.24) \\
1.85(0.89-3.84) \\
2.99(1.40-6.36) \\
1.35(0.61-3.01) \\
2.73(1.31-5.72) \\
2.79(1.37-5.69)\end{array}$ & $\begin{array}{c}1.00 \\
1.83(0.91-3.68) \\
1.70(0.87-3.33) \\
1.90(0.91-3.96) \\
2.91(1.36-6.20) \\
1.25(0.56-2.79) \\
2.30(1.09-4.84) \\
2.59(1.26-5.31)\end{array}$ \\
\hline No. of cars owned & $\begin{array}{r}>=2 \text { cars } \\
1 \text { car } \\
0 \text { cars }\end{array}$ & $\begin{array}{c}63(0.3) \\
117(0.6) \\
79(1.0) \\
\end{array}$ & & & & $\begin{array}{c}1.00 \\
1.19(0.84-1.68) \\
1.19(0.75-1.88) \\
\end{array}$ & $\begin{array}{c}1.00 \\
1.18(0.84-1.67) \\
1.17(0.73-1.87) \\
\end{array}$ & $\begin{array}{c}1.00 \\
1.17(0.82-1.65) \\
1.11(0.69-1.78) \\
\end{array}$ \\
\hline $\begin{array}{r}\text { Area deprivation } \\
2001\end{array}$ & $\begin{array}{r}\text { Least deprived } \\
\text { Intermediate } \\
\text { Most deprived }\end{array}$ & $\begin{array}{c}75(0.4) \\
46(0.5) \\
138(0.7)\end{array}$ & & & & & $\begin{array}{c}1.00 \\
0.93(0.63-1.36) \\
1.05(0.72-1.52)\end{array}$ & $\begin{array}{c}1.00 \\
0.95(0.64-1.40) \\
1.06(0.73-1.54)\end{array}$ \\
\hline $\begin{array}{r}\text { Residential } \\
\text { mobility }\end{array}$ & $\begin{array}{r}\text { No moves } \\
1 \text { move } \\
2 \text { moves } \\
3 \text { moves } \\
4 \text { moves } \\
>5 \text { moves }\end{array}$ & $\begin{array}{l}81(0.4) \\
63(0.5) \\
34(0.5) \\
32(1.0) \\
20(1.3) \\
29(1.9)\end{array}$ & & & & & & $\begin{array}{c}1.00 \\
1.13(0.80-1.60) \\
1.17(0.76-1.80) \\
1.87(1.19-2.93) \\
2.21(1.30-3.76) \\
2.89(1.78-4.69)\end{array}$ \\
\hline
\end{tabular}




\section{Table 4}

Likelihood of cohort members reporting poor mental health at the 2011 Census and the relationship to area level of deprivation at the time of the Censuses controlling for area deprivation at 2001; Data represent odds ratios (95\% Cis).

\begin{tabular}{|c|c|c|c|}
\hline & Least deprived 2011 & Intermediate 2011 & Most deprived 2011 \\
\hline Least deprived 2001 & $1.00^{*}$ & $2.93(1.49-5.78)$ & $3.06(1.59-5.89)$ \\
& $1.0{ }^{\dagger}$ & $2.33(1.16-4.69)$ & $2.03(1.00-4.13)$ \\
& $1.00 \mathrm{~B}$ & $1.99(0.95-4.18)$ & $1.64(0.77-3.52)$ \\
\hline Intermediate 2001 & $1.31(0.57-3.01)$ & 1.00 & $3.13(1.55-6.32)$ \\
& $1.10(0.47-2.58)$ & 1.00 & $1.96(0.92-4.16)$ \\
& $0.93(0.37-2.36)$ & 1.00 & $1.56(0.67-3.59)$ \\
\hline Most deprived 2001 & $1.11(0.66-1.88)$ & $0.98(0.49-1.93)$ & 1.00 \\
& $1.46(0.85-2.51)$ & $1.07(0.54-2.12)$ & 1.00 \\
& $1.16(0.66-2.03)$ & $0.87(0.43-1.75)$ & 1.00 \\
\hline
\end{tabular}

*Adjusted for age and sex

†plus adjustment for LLTI, parental status household size, household tenure/value, and number of cars; ${ }^{B}$ plus adjustment for residential mobility 